\title{
Anti-Müllerian hormone: determination of ovarian reserve in early breast cancer patients
}

\author{
Claudia Bozza', Fabio Puglisi ${ }^{1,2}$, Matteo Lambertini ${ }^{3}$, Etin-Osa Osa ${ }^{4}$, Massimo Manno ${ }^{5}$ \\ and Lucia Del Mastro ${ }^{6}$ \\ ${ }^{1}$ Department of Oncology, University Hospital of Udine, Udine, Italy \\ ${ }^{2}$ Department of Medical and Biological Sciences, University of Udine, Udine, Italy \\ ${ }^{3}$ Department of Medical Oncology (UO Oncologia Medica A), IRCCS AOU San Martino-IST, Largo Rosanna Benzi, \\ 10, 16132 Genova, Italy \\ ${ }^{4}$ Department of Radiation Oncology, New York University School of Medicine, New York, New York, USA \\ ${ }^{5}$ Mother and Child Department, Pordenone Hospital, Pordenone, Italy \\ ${ }^{6}$ Department of Medical Oncology (SS Sviluppo Terapie Innovative), IRCCS AOU San Martino-IST, Genova, Italy
}

\author{
Correspondence \\ should be addressed \\ to M Lambertini \\ Email \\ matteo.lambertini@ \\ hsanmartino.it
}

\begin{abstract}
Breast cancer is the most common invasive cancer in women of reproductive age. In young women, chemotherapy may induce amenorrhea: it is still uncertain how to assess menopausal status in these patients despite the importance of its definition for choosing appropriate endocrine treatment. In the development of sensitive biomarkers for fertility and ovarian reserve, anti-Müllerian hormone (AMH) is considered a promising marker of ovarian reserve. The clearest data regarding a clinical use of $\mathrm{AMH}$ are related to the measurement of the ovarian pool in women who undergo IVF: the available data, also in breast cancer patients, seem to suggest that $\mathrm{AMH}$ measurement, before gonadotropin administration, can be a useful marker for the prediction of women at risk for poor-response or no response to ovarian stimulation. The utility of $\mathrm{AMH}$ as a potential marker of chemotherapy-induced ovarian follicular depletion and an early plasma marker of chemotherapy-induced gonadal damage has been evaluated both in young women after treatment for cancer in childhood and in young survivors of hematological malignancies and solid tumors. Several studies have demonstrated a potential utility of $\mathrm{AMH}$, inhibin, or follicle-stimulating factor as biomarkers predicting infertility risk in breast cancer patients, but the studies conducted so far are not conclusive. Further studies are needed in order to define the regimen-specific action of chemotherapy on AMH levels, the percentage of post-treatment recovery of plasma levels of the hormone, and the relationship between menopausal status and $\mathrm{AMH}$.
\end{abstract}
Key Words
- breast
- growth factor
- hormone action
- oncology

Endocrine-Related Cancer

(2014) 21, R51-R65

\section{Introduction}

During the last 50 years, we have witnessed a rise in the mean age at which women deliver their first child (Johnson et al. 2012). Female fertility begins to decline from the early 1920s due to decreasing ovarian reserve and for this reason, the infertility problem is now more common (Gougeon et al. 1994, te Velde \& Pearson 2002).

Breast cancer is the most common invasive cancer seen in women of reproductive age (Smigal et al. 2006): 
$\sim 6 \%$ of women with breast carcinoma are diagnosed before the age of 40 (Surveillance, Epidemiology and End Results (SEER) web site, available online: http://www.seer. cancer.gov) and recent data have shown that the incidence of breast cancer diagnosed in young women is increasing (Merlo et al. 2012). The increasing number of earlier diagnosis and adjuvant therapy are expected to increase the number of breast cancer survivors (Jemal et al. 2003, Ganz \& Hahn 2008). In young women, chemotherapy may induce amenorrhea and it is still uncertain how to assess menopausal status in these patients despite the fact that the definition of the menopausal status is relevant for choosing appropriate antihormonal treatment (Amir et al. 2009, 2010).

As greater emphasis is placed on the quality of life of breast cancer survivors due to higher survival rates, fertility preservation has become a key component of cancer care (Gracia \& Jeruss 2013, Rodriguez et al. 2013, Salama et al. 2013). In the development of sensitive biomarkers for fertility and ovarian reserve, anti-Müllerian hormone $(\mathrm{AMH})$ is considered a promising marker of ovarian reserve (Anderson et al. 2012, Garcia et al. 2012).

The assessment of ovarian function and reserve, the chance of fertility preservation, and the role of $\mathrm{AMH}$ are emerging topics in premenopausal women with breast cancer who undergo chemotherapy and hormonal treatment.

\section{Determination of menopausal status in patients treated for early breast cancer}

Menopause is a cornerstone both in breast cancer pathophysiology and in clinical management (Clemons $\&$ Simmons 2007). For example, late menopause is traditionally considered as a risk factor for breast cancer development and is normally defined as the absence of menstrual periods for 12 consecutive months with no cause (Randolph et al. 2006).

National Comprehensive Cancer Network (NCCN) criteria consider the following to determine menopause: age $\geq 60$ or a prior bilateral oophorectomy, or age $<60$ years and amenorrhea for $\geq 12$ months in the absence of chemotherapy, tamoxifen, toremifene, or ovarian suppression and follicle-stimulating hormone (FSH) and estradiol $\left(\mathrm{E}_{2}\right)$ levels in postmenopausal range (NCCN Guidelines, available at: http://www.nccn.org/professional/physician_gls/f_guidelines.asp).

Adjuvant chemotherapy in premenopausal patients can cause amenorrhea and decrease ovarian reserve (Wallace et al. 2005). The incidence of a return of menses after adjuvant chemotherapy is a function of age and regimen type (Amir et al. 2009, 2010).

If premenopausal status is present at the beginning of chemotherapy, amenorrhea is not a reliable indicator of menopause (Smith et al. 2006). Therefore, in breast cancer management, menopausal status can be defined as the permanent and profound decrease in ovarian estrogen synthesis.

Biochemical tests can help in the measurement of hormonal levels, but these tests are limited because serial determinations over time are needed and there are no cutoff points for FSH, luteinizing hormone (LH), and $\mathrm{E}_{2}$.

Furthermore, the use of tamoxifen after chemotherapy could be associated with a marked fall in FSH levels in patients with chemotherapy-induced amenorrhea. However, the effect of tamoxifen on hormone levels is not clear. $E_{2}$ levels can be elevated as result of the crossreactivity of tamoxifen and its metabolites in the $\mathrm{E}_{2}$ assay (Lum et al. 1997). Generally, hormone levels may not reliably reflect menopausal status in breast cancer patients on tamoxifen (Hadji et al. 2012).

\section{AMH and fertility}

AMH is a glycoprotein of the transforming growth factor $\beta$ family that seems to reflect the continuous non-cyclical growth of small follicles (Massague 1990) and can be considered an indirect index of the size of the resting primordial follicle pool. Accordingly, AMH represents a marker of ovarian reserve. In females, $\mathrm{AMH}$ is produced by granulosa cells and released into the circulation from the time of birth until menopause (Rajpert-De Meyts et al. 1999).

The major production is seen at the preantral and small antral follicle stages, and its expression decreases as follicles reach antral and preovulatory stages (Weenen et al. 2004).

An important role of AMH is to protect the number of primordial follicles by inhibiting their rapid recruitment, sparing the follicle pool exhaustion (Durlinger et al. 1999). In addition, $\mathrm{AMH}$ prevents premature depletion of the follicle pool by decreasing follicular sensitivity to FSH. By this negative influence on initial recruitment, $\mathrm{AMH}$ controls the number of preantral and small antral follicles that do undergo atresia and continue to grow into the preovulatory stage (Durlinger et al. 2001).

It is difficult to measure ovarian reserve directly, but hormonal markers ( $\mathrm{FSH}, \mathrm{E}_{2}$, and inhibin $\mathrm{B}$ ) and ultrasonographic tests (antral follicle count (AFC) and measurement

Published by Bioscientifica Ltd. 
of ovarian volume) can help to determine, indirectly or directly, the size of the antral follicle pool.

$\mathrm{FSH}, \mathrm{E}_{2}$, and inhibin $\mathrm{B}$ indirectly reflect ovarian reserve, but their cyclical fluctuations tend to make the determination of ovarian reserve difficult. In contrast, AMH better reflects the longitudinal decline of oocyte/ follicle pool over time (La Marca et al. 2006). Indeed, AMH levels are stable across the menstrual cycle and are not affected by pregnancy or treatment with gonadotropinreleasing hormone agonists. In addition, although an effect of combined oral contraceptive pill on ovarian reserve has been described (Bentzen et al. 2012, Deb et al. 2012, Kallio et al. 2013), its use seems to be associated with minimal suppression of the later FSH-dependent stages of follicle development (Arbo et al. 2007, Streuli et al. 2008, Sowers et al. 2010, Li et al. 2011, Shaw et al. 2011). It is still debated if clinical and behavioral variables, such as BMI and smoking habit, may influence AMH plasma levels.

\section{AMH and assisted reproductive technology}

Currently, much of the value of AMH lies in its relation to the declining ovarian pool with age, and thus its potential ability to predict future reproductive outcomes. The clearest data regarding a clinical use of $\mathrm{AMH}$ are related to the measurement of the ovarian pool in women who undergo IVF. In recent years, extremely interesting data have been published showing the possible clinical application of AMH measurement in the prediction of quantitative and qualitative ovarian response in assisted reproductive technologies (ART; La Marca et al. 2010). Several retrospective and prospective studies have found a strong positive correlation between the number of retrieved oocytes and basal AMH serum levels in women undergoing ovarian stimulation (La Marca et al. 2010).

Elevated plasma AMH levels are associated with better fertility rates (Lee et al. 2009). Seifer et al. (2002), the first authors reporting an association between serum AMH levels and ovarian response to gonadotrophin, showed that AMH levels were 2.5-fold higher in patients with at least 11 oocytes compared with those with six oocytes or fewer retrieved. These results were successively confirmed by many authors in several retrospective and prospective studies.

AMH seems to reflect not only quantitative but also qualitative ovarian responsiveness in ART. Several studies found a significant positive correlation between AMH levels and the quality of oocytes (Hazout et al. 2004, Ebner et al. 2006, Silberstein et al. 2006, Cupisti et al. 2007, Fanchin et al. 2007, Lekamge et al. 2007) and embryo morphology (Silberstein et al. 2006). However, this relationship has not been confirmed by other authors (Smeenk et al. 2007, Lie Fong et al. 2008a), and the predictive value of serum AMH on oocyte competence and embryo quality remains controversial (La Marca et al. 2010).

The possible correlation between AMH levels and embryo/oocyte cryopreservation cycle (ECC) outcomes has also been evaluated in breast cancer patients undergoing stimulation with letrozole and FSH for fertility preservation (Lee et al. 2011). Lee et al. retrospectively analyzed the correlation between AMH levels during the early-follicular phase of the menstrual cycles and AFC and ECC outcomes in 41 women with breast cancer before adjuvant treatment. AMH and AFC showed a stronger correlation with the total number of oocytes and the number of mature oocytes retrieved than age, FSH, and inhibin B levels. Patients with an ovarian response to stimulation classified as low (less than four mature oocytes retrieved) had AMH levels $\leq 1.2 \mathrm{ng} / \mathrm{ml}$; in contrast, $\mathrm{AMH}$ level $>1.2 \mathrm{ng} / \mathrm{ml}$ before chemotherapy was associated with a high possibility of obtaining more than four mature oocytes (Lee et al. 2011). The authors concluded that together with AFC as a biophysical marker in breast cancer patients, $\mathrm{AMH}$ is the most reliable serum marker of ECC outcomes. Therefore, AMH and AFC appear to be useful in counseling breast cancer patients who want to undergo ovarian stimulation for fertility preservation (Lee et al. 2011).

In conclusion, the available data seem to suggest that $\mathrm{AMH}$ measurement before gonadotropin administration can be a useful marker for the prediction of women at risk for poor-response or no response to ovarian stimulation. Although few data are available in cancer patients undergoing cryopreservation procedures for fertility preservation before cancer treatments, AMH could help physicians to better counsel these women.

\section{AMH and chemo-induced gonadal damage in cancer patients}

Many of the chemotherapeutic regimens used in the treatment of common cancers are gonadotoxic and increase the risk of premature ovarian failure in young women (Lee et al. 2006).

The utility of hormone and ultrasound measurements to assess ovarian reserve in cancer survivors is well known as even in the presence of normal ovarian function (regular menstrual cycles), ovarian reserve of these patients may be altered due to the treatment received.

Published by Bioscientifica Ltd. 
Hormone level analysis ( $\mathrm{FSH}, \mathrm{E}_{2}$, and inhibin $\mathrm{B}$ ) and ultrasound measurements in these patients show a diminished ovarian reserve, indicating that adult survivors with spontaneous cycles may have a shortened reproductive span and an early menopause (Larsen et al. 2003a,b). The utility of AMH as a potential marker of chemotherapyinduced ovarian follicular depletion has been evaluated both in young women after treatment for cancer in childhood and in young survivors of hematological malignancies and solid tumors (Table 1).

Three studies investigated ovarian reserve in adults after treatment for childhood cancer (Bath et al. 2003, van Beek et al. 2007, Lie Fong et al. 2009): all studies showed that cancer survivors who had been treated with chemotherapy during childhood had significantly lower ovarian reserve as determined by lower AMH levels than healthy women.

Gracia et al. (2012) carried on a cross-sectional analysis to compare measures of ovarian reserve $\left(\mathrm{E}_{2}, \mathrm{FSH}\right.$, inhibin $\mathrm{B}, \mathrm{AMH}$, and $\mathrm{AFC}$ ) in young cancer survivors with those in unexposed females of similar age and with a cohort of late-reproductive-age women. A total of 71 cancer survivors (47 patients with hematological malignancy and 24 with solid tumors), 67 similarly aged unexposed controls, and 69 regularly menstruating women of late reproductive age were included. In adjusted models, cancer survivors had significantly higher FSH and lower AMH $(0.81$ vs $2.85 \mathrm{ng} / \mathrm{ml} ; P<0.001)$ and AFC levels compared with unexposed women of similar age. Increased dose of alkylating agent was associated with increased levels of FSH and decreased levels of AMH. AMH levels were not significantly different between women previously exposed to high-dose cancer therapy and 40-42-year-old controls (Gracia et al. 2012).

Recently, Behringer et al. (2013) have provided important data on the impact of currently used chemotherapy in Hodgkin lymphoma on gonadal function. The authors evaluated hormone parameters, menstrual cycle, symptoms of hypogonadism, and offspring in women younger than 40 years of age and men younger than 50 years of age at diagnosis in ongoing remission at least 1 year after therapy within two clinical German studies for early- and advanced-Hodgkin lymphoma. Out of 1323 patients enrolled, 562 were women. The authors showed that hormone levels correlated with the intensity of chemotherapy, but also, age was a relevant factor for reduced ovarian reserve. Specifically, AMH levels were significantly worse after more intensive alkylating agentcontaining chemotherapy and with older age. However, pregnancies in women with low or undetectable $\mathrm{AMH}$ levels were reported, underlining the need to further analyze the relevance of AMH assessment in female survivors of cancer. The authors concluded that 'AMH is obviously not suited to predict fertility in individual patients; however, low AMH levels might indicate a reduced ovarian reserve and thus an increased risk of future premature ovarian failure' (Behringer et al. 2013).

AMH seems to be an early and sensitive plasma marker of gonadal damage after chemotherapeutic treatment, as AMH falls very rapidly after the initiation of chemotherapy. There are available data both for patients with hematological malignancies and solid nonbreast tumors and for children treated for cancer (Table 2).

Lie Fong et al. (2008b) measured serum AMH levels in 25 patients with hematological malignancies before and after cancer treatments and compared them with normo-ovulatory controls to assess subclinical ovarian damage in patients treated with gonadotoxic agents. AMH concentrations in all patients before treatment were lower than in controls, and although menstrual cyclicity was restored in most patients treated with chemotherapy, median serum AMH levels were lower in patients than in controls. All 12 patients who underwent stem cell transplantation after total body irradiation developed premature ovarian failure and undetectable serum AMH concentrations (Lie Fong et al. 2008b).

Decanter et al. (2010) published a study in which AMH was measured to characterize the evolution of follicular depletion in 30 young patients treated for lymphoma (mean age 24), assigned to an ABVD (adriamicyn, bleomycin, vinblastine, dacarbazine) protocol or to a non-ABVD protocol (a regimen including cyclophosphamide). Plasma levels of AMH were measured before and during chemotherapy until a period of 1 year after the end of treatment. The hormone levels quickly decreased in all patients, but in patients treated with ABVD, returned to normal 1 year after the end of treatment. This analysis clearly demonstrates the toxicity of alkylating agent-based therapy (Decanter et al. 2010).

Rosendahl et al. (2010) evaluated AMH and hormonal markers in 17 patients with a hematological malignancy or breast cancer before, during, and after chemotherapy. They showed that AMH and inhibin B levels immediately declined after chemotherapy administration, indicating direct chemotherapy-induced damage to the granulosa cells of the growing follicles. Furthermore, they showed that high pretreatment AMH levels were predictive of higher AMH levels during recovery of ovarian function after chemotherapy (Rosendahl et al. 2010).

Published by Bioscientifica Ltd. 


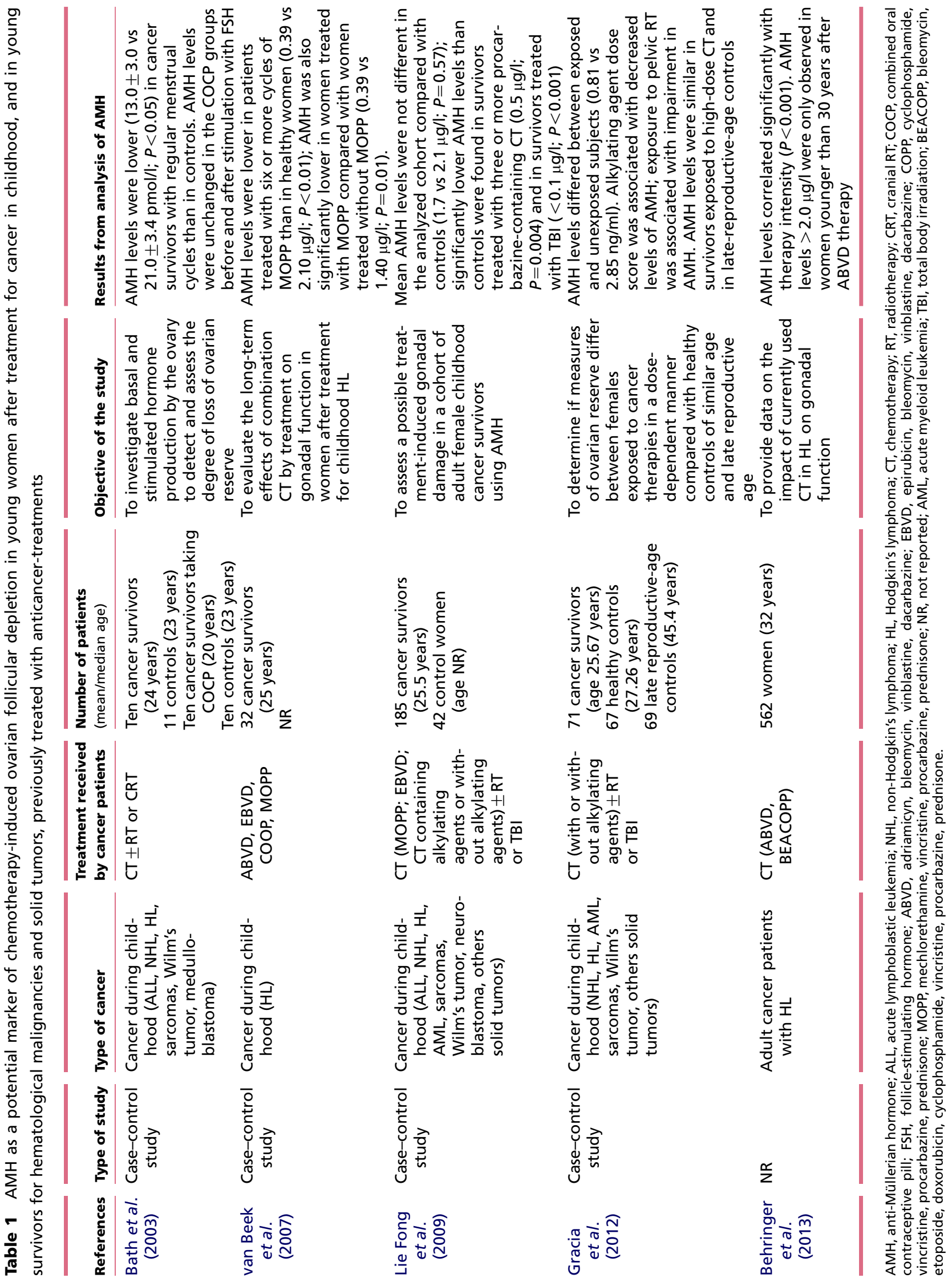



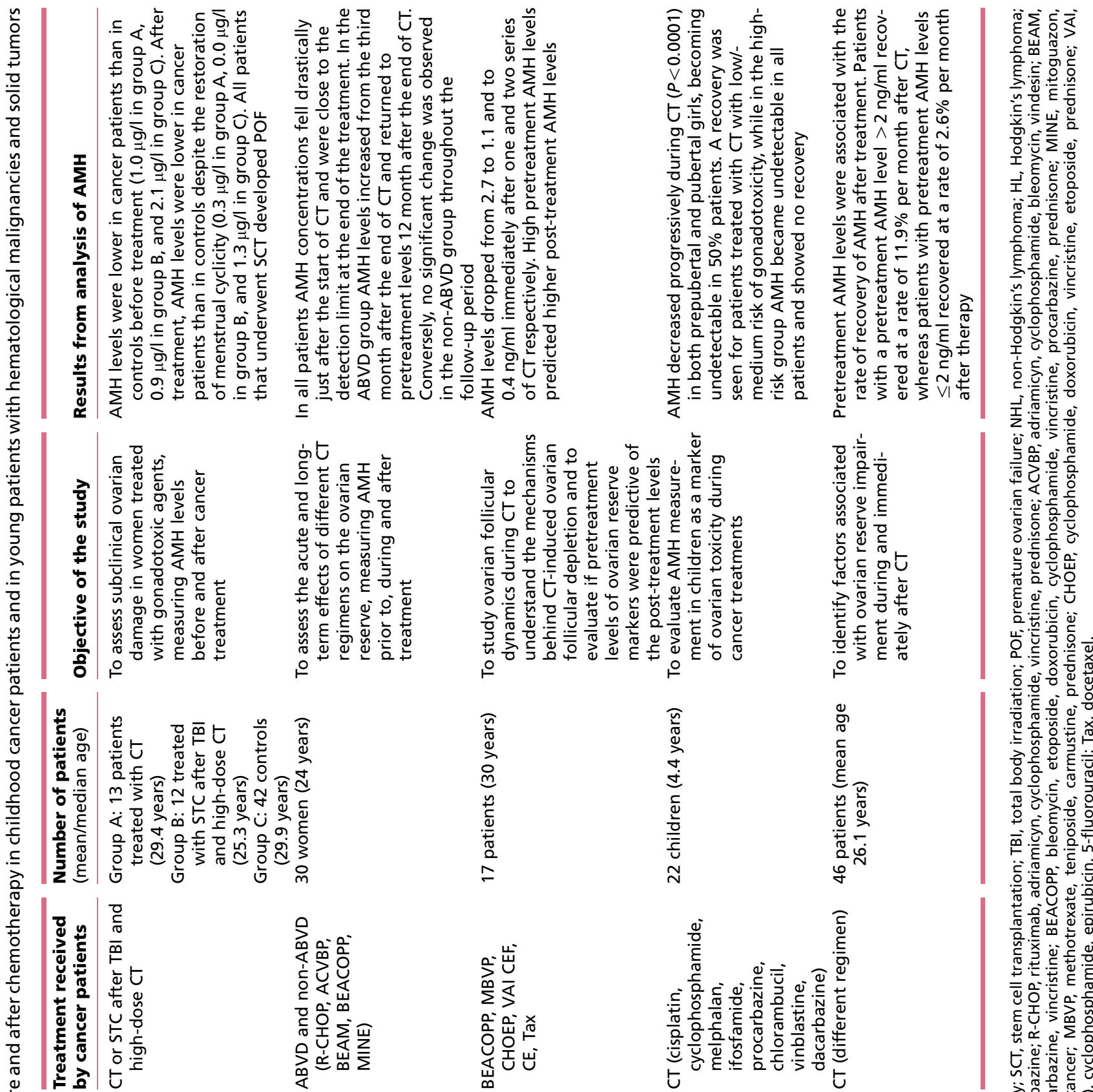

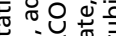

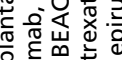

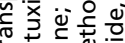

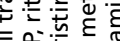

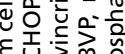

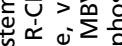

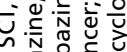

응은 윤

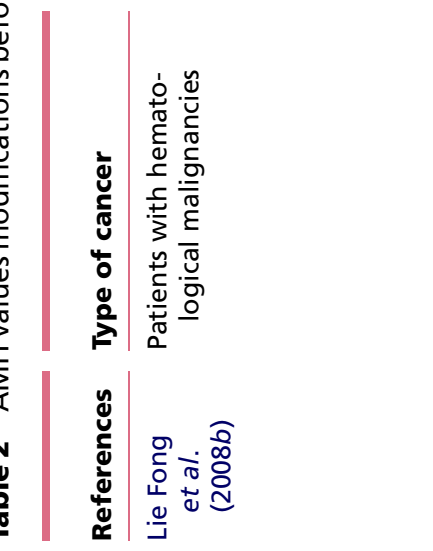

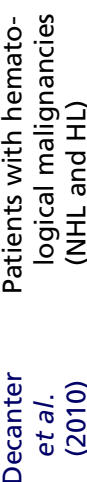

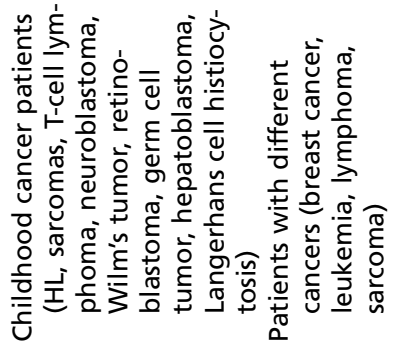

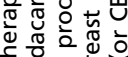

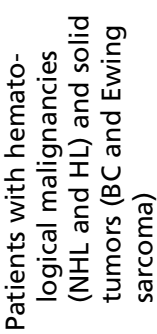

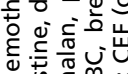

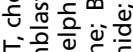

ヒ匕.气

बें

हो

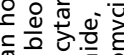

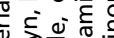

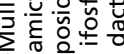

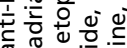

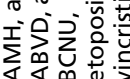


Brougham et al. (2012) prospectively evaluated AMH levels in children as a marker of ovarian reserve during cancer treatment. A total of 22 patients with a median age of 4.4 years were enrolled before initiation of cancer treatment. Serum AMH levels were measured at diagnosis, after each chemotherapy course and during follow-up. Risk of gonadotoxicity was classified as low/medium or high based on chemotherapy agent, cumulative dose, and radiotherapy involving the ovaries. The authors demonstrated that AMH was detectable in girls of all ages but decreased progressively during chemotherapy in both preand post-pubertal girls, eventually becoming undetectable in $50 \%$ of patients. AMH levels showed no recovery in the high-risk group, while there was a recovery in the low/medium risk group after the completion of chemotherapy (Brougham et al. 2012). Interestingly, authors observed that $\mathrm{AMH}$, due to the physiological quiescence of the hypothalamic-pituitary-gonadal axis at this age, was the only reliable biomarker for ovarian damage evaluation in prepubertal children (Brougham et al. 2012).

Recently, Dillon et al. (2013) have evaluated factors (FSH, LH, $\mathrm{E}_{2}$, inhibin $\mathrm{B}$, and $\mathrm{AMH}$ ) associated with ovarian reserve impairment during and immediately after chemotherapy. All measures of ovarian reserve demonstrated statistically significant changes during chemotherapy: alkylating agent exposure and baseline ovarian reserve were acutely associated with the magnitude of impairment. Particularly, pretreatment AMH levels were associated with the rate of recovery of $\mathrm{AMH}$ after treatment (Dillon et al. 2013).

In conclusion, a fall in AMH levels during chemotherapy with recovery dependent on the toxicity of the regimen used was detected not only in young cancer women but also in prepubertal girls, and, generally, AMH concentrations are reduced in women following treatment of cancer, either in childhood or adulthood, with low AMH concentrations most consistently seen following total body radiation.

\section{AMH, chemo-induced gonadal damage, and adjuvant therapy for breast cancer}

In the last few years, some studies have tried to better define the association between ovarian function and AMH in breast cancer patients (Table 3). The impact of cancer treatments on gonodal function of young breast cancer patients is well known, but it is still not known if the malignancy itself impacts ovarian reserve. Before counseling patients for fertility preservation, it is important to consider whether ovarian reserve is impacted by cancer.
To explore this issue by determining if $\mathrm{AMH}, \mathrm{FSH}$, and inhibin B levels differ in young women with and without breast cancer, Su et al. (2013) performed a cross-sectional study involving 207 participants, 108 women with breast cancer and 99 healthy women. The authors showed that mean AMH levels were not significantly different between breast cancer participants and healthy controls (0.85 vs $0.76 \mathrm{ng} / \mathrm{ml}, P=0.60)$, although AMH may be lower with breast cancer status in women older than 37 years (Su et al. 2013).

Data are available regarding the use of $\mathrm{AMH}$ as a marker to better assess ovarian reserve, even in the presence of regular menstrual cycles, in breast cancer patients who undergo anticancer treatments.

Anderson \& Cameron (2011) recruited 56 premenopausal women with early-stage breast cancer in a 5-year prospective study of ovarian function and bone mass, in which 42 patients received adjuvant chemotherapy. Hormonal and biophysical markers of ovarian function at 4-5 years of follow-up were analyzed in relation to menstrual activity. Higher levels of $\mathrm{AMH}$, inhibin B, and $\mathrm{E}_{2}$ and lower levels of FSH were observed in women with ongoing menses vs women that became amenorrheic after chemotherapy, confirming the validity of menstrual diary data. The authors' conclusion was that the AMH level before adjuvant chemotherapy predicts long-term ovarian function (Anderson \& Cameron 2011).

Partridge et al. (2010) compared markers of ovarian reserve between 20 survivors of breast cancer exposed to cytotoxic chemotherapy (50\% received tamoxifen) and 20 matched controls in a cross-sectional evaluation. This study demonstrated that premenopausal breast cancer survivors have diminished ovarian reserve compared with controls. Interestingly, survivors receiving tamoxifen had lower AFC, AMH, inhibin B levels and higher $\mathrm{E}_{2}$ levels than non-tamoxifen-treated survivors (Partridge et al. 2010).

The same group has recently published an interim analysis of an ongoing prospective multi-center cohort study, in which breast cancer patients younger than 41 years of age had blood drawn and surveys about their menstrual cycle collected 1 year after diagnosis (Ruddy et al. 2012). A total of 199 women with a median age of 37 years were eligible in the analysis. The majority of the women received chemotherapy (74\%) and 56\% received tamoxifen. Median $\mathrm{AMH}$ and $\mathrm{E}_{2}$ levels were significantly lower and FSH levels were significantly higher in women with amenorrhea (defined as more than 6 months between blood drawn and last menstrual period). The authors concluded that $\mathrm{AMH}, \mathrm{E}_{2}$, and $\mathrm{FSH}$ are promising

Published by Bioscientifica Ltd. 


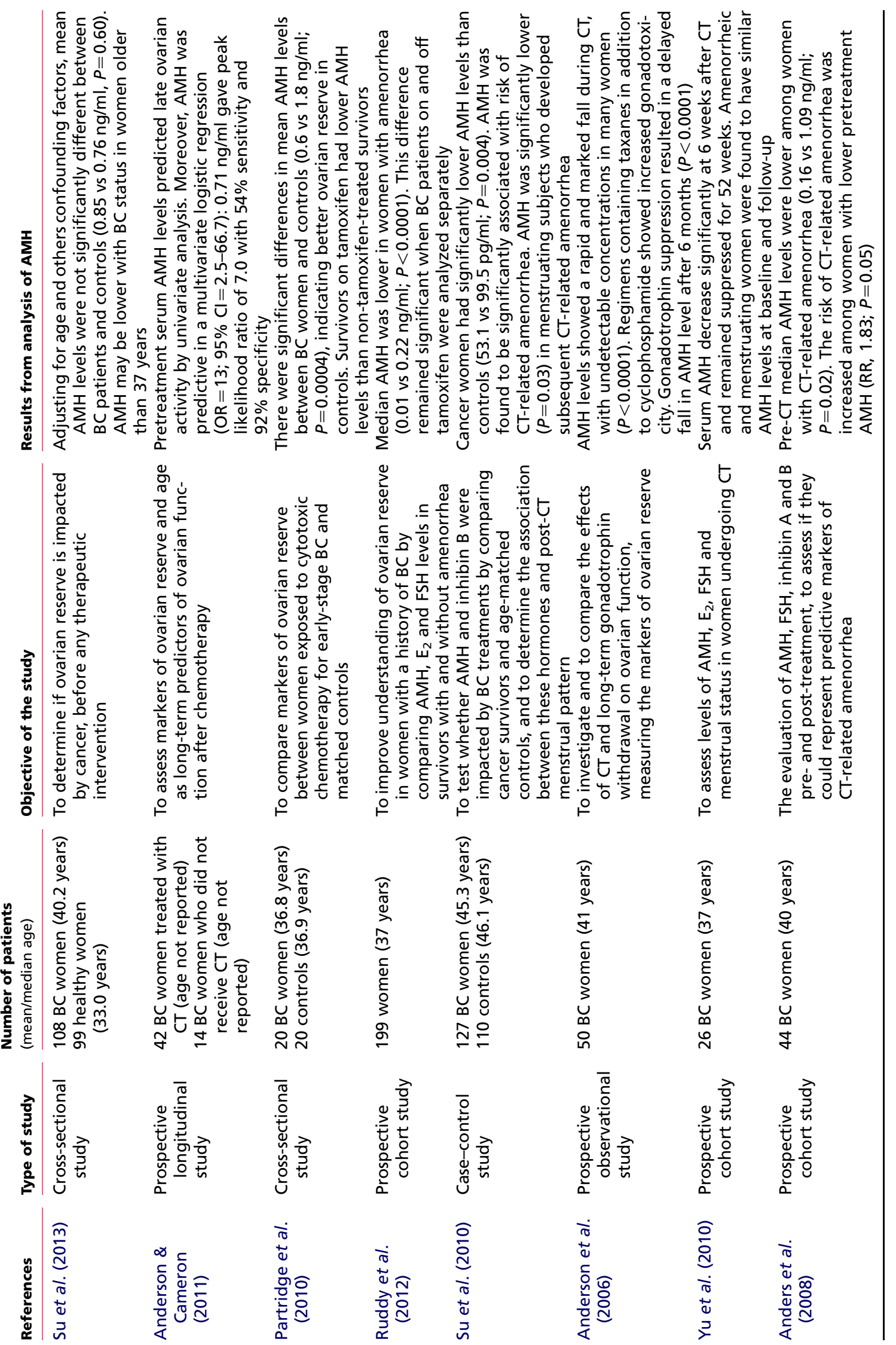




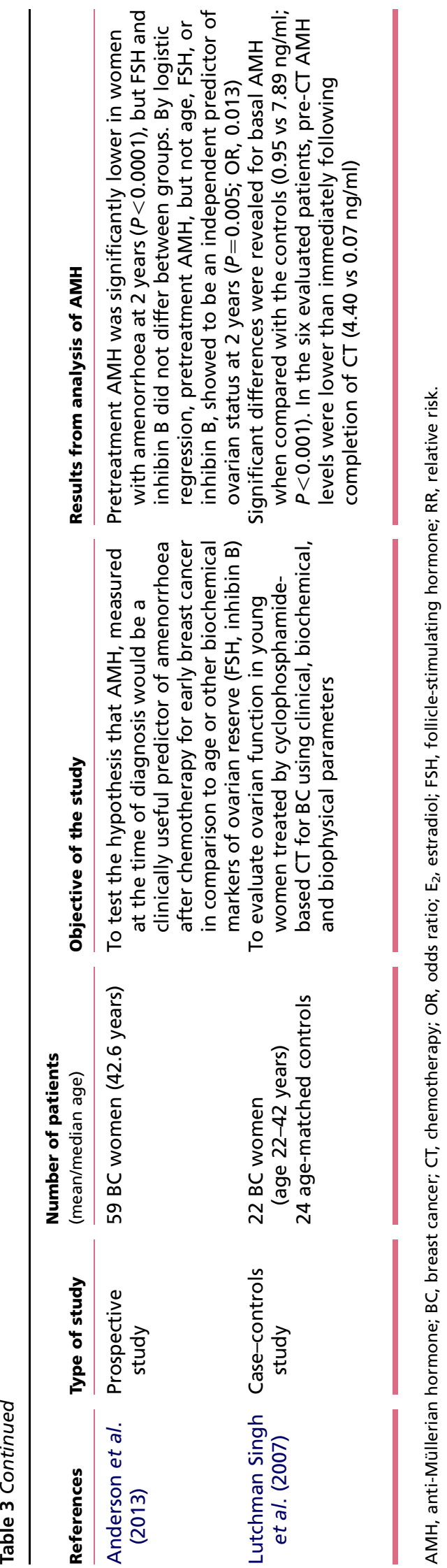

http://erc.endocrinology-journals.org DOI: 10.1530/ERC-13-0335
(C) 2014 Society for Endocrinology Printed in Great Britain biomarkers to define amenorrhea and residual ovarian function in breast cancer survivors (Ruddy et al. 2012).

Su et al. (2010) analyzed 127 breast cancer patients post chemotherapy that were premenopausal at diagnosis. The primary endpoint was chemotherapy-related amenorrhea (CRA). Compared with age-matched controls, AMH levels were significantly lower $(P<0.03)$ and FSH levels were significantly higher $(P<0.04)$ in menstruating cancer patients who developed CRA (Su et al. 2010).

As in hematological and pediatric cancer patients, in breast cancer patients AMH seems to be an early and sensitive plasma marker of gonadal damage after chemotherapeutic treatment.

Anderson et al. (2006) conducted a study in which markers of ovarian reserve $\left(\mathrm{AMH}, \mathrm{E}_{2}, \mathrm{FSH}\right.$, inhibin $\mathrm{B}$, and $\mathrm{AFC}$ ) were measured in 50 patients with early breast cancer who received adjuvant treatment. Of these patients, 42 received chemotherapy and eight received hormonal treatment. Patients were reevaluated 3, 6, 9, and 12 months after starting chemotherapy. AMH demonstrated its role as an early indicator of chemotherapy-induced ovarian follicle loss, and the authors suggested that FSH and $\mathrm{AMH}$ concentration measurements would be useful for the comparison of ovarian toxicity of different chemotherapy regimens (Anderson et al. 2006). Furthermore, they found that the addition of a taxane to a regimen containing cyclophosphamide seems to be more gonadotoxic, resulting in lower plasma AMH levels. In patients treated with analogs of LH-releasing hormone (LHRHa), AMH concentrations showed a delayed fall (Anderson et al. 2006).

$\mathrm{Yu}$ et al. (2010) demonstrated that serum AMH decreased significantly at 6 weeks after chemotherapy and remained suppressed for 52 weeks in 26 women treated for early breast cancer. Amenorrheic and menstruating women were found to have similar AMH values at baseline and at follow-up.

Anders et al. (2008) analyzed 44 early-stage breast cancer patients at risk of CRA. FSH, $\mathrm{E}_{2}$, inhibin A and B, and $\mathrm{AMH}$ levels were prospectively evaluated prechemotherapy, post-chemotherapy, 6 months, and 1 year after the end of chemotherapy. Pre-chemotherapy median inhibin $\mathrm{B}$ and $\mathrm{AMH}$ values were lower among women experiencing CRA $(P=0.03$ and $P=0.02$ respectively), thus indicating that these markers might be predictive of CRA among premenopausal women undergoing chemotherapy for breast cancer (Anders et al. 2008).

Recently, Anderson et al. (2013) have shown that pretreatment $\mathrm{AMH}$ was a useful predictor of long-term

Published by Bioscientifica Ltd. 
post-chemotherapy loss of ovarian function after chemotherapy in women with early breast cancer. Pretreatment AMH showed a significant positive correlation with menses: pretreatment AMH was significantly lower in women with amenorrhoea at 2 years $(P<0.0001)$; by logistic regression, pretreatment AMH was shown to be an independent predictor of ovarian status at 2 years $(P=0.005)$ (Anderson et al. 2013).

Lutchman Singh et al. (2007) evaluated ovarian function in 22 young breast cancer women treated with chemotherapy and in 24 age-matched controls. The patients were recruited before and after the completion of chemotherapy and serum samples were analyzed for FSH, LH, E 2 , inhibin A and B, and AMH. Significantly higher basal FSH values $(P<0.001)$ and lower AMH $(P<0.001)$ and inhibin B $(P<0.001)$ levels were found in breast cancer patients than in the control group, indicating their potential use as markers of ovarian reserve in young women with breast cancer (Lutchman Singh et al. 2007).

In conclusion, several studies have demonstrated a potential utility of $\mathrm{AMH}$, inhibin, or FSH as biomarkers predicting infertility risk in breast cancer patients. These studies demonstrated that breast cancer itself does not seem to have a negative impact on ovarian function before starting anticancer treatments, and that increased rates of CRA have been associated with low pretreatment AMH and inhibin levels, and high FSH levels. BRCA1positive patients could be considered an exception due to their pre-chemotherapy that reduced AMH levels (Oktay et al. 2010): reduced ovarian reserve and premature ovarian aging in these patients could be related to an impaired repair of DNA double stand breaks as a consequence of BRCA1 mutation (Titus et al. 2013). Furthermore, AMH was shown to have a potential role as an early indicator of chemotherapy-induced follicle loss; finally, decreased AMH and inhibin levels and increased FSH levels compared with age-matched healthy controls seem to correlate with decreased ovarian reserve in patients previously treated with chemotherapy.

\section{AMH and ovarian suppression with the LHRHa in breast cancer patients}

The administration of LHRHa is one of the available fertility preservation techniques for young breast cancer patients (Lambertini et al. 2013) although it remains controversial whether this should be considered a standard or still an experimental strategy (Loren et al. 2013).

Data on hormone levels are available from several trials that evaluated the efficacy of LHRHa as a fertility preservation strategy in breast cancer patients; however, data specifically relating to the impact of LHRHa treatment on AMH levels are very limited (Turner et al. 2013). In studies that included $\mathrm{AMH}$ assessment, its evaluation was carried out only in a minority of patients and was reported only as exploratory or in abstract form (Table 4).

Table 4 AMH evaluation in clinical trials that evaluated LHRHa for the prevention of CT-induced early menopause

\begin{tabular}{|c|c|c|c|}
\hline References & $\begin{array}{l}\text { Number of patients with AMH } \\
\text { evaluation (total of patients } \\
\text { enrolled in the clinical study) }\end{array}$ & $\begin{array}{l}\text { Comparison by } \\
\text { treatment arms }\end{array}$ & Results from analysis of AMH \\
\hline $\begin{array}{l}\text { Gerber et al. } \\
\text { (2011) }\end{array}$ & $17(60)$ & No & $\begin{array}{l}\text { AMH strongly correlated with age, with lower AMH levels in } \\
\text { older patients. An AMH level }>0.2 \mu \mathrm{g} / \mathrm{l} \text { was seen in } 3 \text { of } \\
9(33 \%) \text { patients in the group without goserelin vs } 4 \text { of } \\
8(50 \%) \text { patients in the goserelin group }\end{array}$ \\
\hline $\begin{array}{l}\text { Elgindy et al. } \\
\qquad(2013)\end{array}$ & NR (100) & Yes & $\begin{array}{l}\text { AMH decreased significantly at } 1 \text { year after the end of CT in all } \\
\text { groups regardless of treatment arms ( } 2-2.3 \text { vs } 0.2-0.4 \mathrm{ng} / \mathrm{ml} \\
\text { for pre- and post- CT respectively). No differences in AMH } \\
\text { levels between control arms and LHRHa arms at } 12 \text { months } \\
\text { after the end of CT }\end{array}$ \\
\hline $\begin{array}{l}\text { Leonard et al. } \\
\qquad(2012)\end{array}$ & $117(227)$ & No & $\begin{array}{l}\text { AMH was lower following } C T \text { than before } C T \text { initiation } \\
(0.40 \pm 0.65 \text { vs } 1.38 \pm 1.82 \mathrm{ng} / \mathrm{ml} ; P<0.001) \text {. Pre-CT AMH } \\
\text { was a significant predictor of post-treatment amenorrhea } \\
(P=0.001)\end{array}$ \\
\hline $\begin{array}{l}\text { Giraudi et al. } \\
\qquad(2009)\end{array}$ & $26(281)$ & No & $\begin{array}{l}\text { AMH levels were significantly lower in old patients } \\
\text { ( } \geq 41 \text { years) as compared to younger ones. After } \mathrm{CT} \text {, } \\
\text { mean value of AMH significantly decreased from } 2.04 \text { to } \\
0.59 \mathrm{ng} / \mathrm{ml}(P=0.0003) \text {. The mean decrease of AMH levels } \\
\text { was not affected by the type of CT regimens }\end{array}$ \\
\hline
\end{tabular}

LHRHa, analogs of luteinizing hormone; CT, chemotherapy; AMH, anti-Müllerian hormone; NR, not reported.

http://erc.endocrinology-journals.org DOI: 10.1530/ERC-13-0335
(C) 2014 Society for Endocrinology Printed in Great Britain
Published by Bioscientifica Ltd. 
In the GBG 37 ZORO study, 60 hormone-insensitive breast cancer patients younger than 46 years of age were allocated to receive chemotherapy with or without goserelin (Gerber et al. 2011). Out of 60 patients, 17 were accessible for hormone assessment (inhibin B, AMH, $\mathrm{E}_{2}$, and FSH) and follicle count by ultrasound during followup to estimate ovarian function. Out of these 17 patients, eight received goserelin and nine were treated without LHRHa. AMH correlated strongly with age, with lower AMH levels in older patients. An AMH level $>0.2 \mu \mathrm{g} / \mathrm{l}$ was seen in 3 of $9(33 \%)$ patients in the group without LHRHa vs 4 of $8(50 \%)$ patients in the goseriln group respectively. A direct comparison between treatment arms was not possible due to limited patient numbers. The AFC was available in ten patients. Two patients had a high follicle count $(\geq 4)$ and AMH level $>0.2 \mu \mathrm{g} / \mathrm{l}$ (Gerber et al. 2011).

Elgindy et al. (2013) randomly assigned 100 hormoneinsensitive breast cancer patients younger than 40 years of age to receive triptorelin during cyclophosphamide-based chemotherapy (with the addition of an LHRH antagonist for a few days in patients who started chemotherapy earlier than 10 days before study inclusion). AMH decreased significantly at 1 year post chemotherapy in all groups regardless of treatment arms (2-2.3 vs $0.2-0.4 \mathrm{ng} / \mathrm{ml}$ for pre- and post-chemotherapy respectively). No difference in AMH levels was seen between control arms and LHRHa arms at 12 months after the end of chemotherapy (Elgindy et al. 2013).

In the OPTION trial, 227 premenopausal breast cancer patients were randomly assigned to receive (neo)-adjuvant chemotherapy with or without goserelin (Leonard et al. 2010). AMH was measured in 117 patients pretreatment and 1 year following initiation of chemotherapy (Leonard et al. 2012). No differences in pretreatment AMH levels were seen between control and goserelin-treated groups. $\mathrm{AMH}$ levels were lower following chemotherapy than before the initiation of chemotherapy $(0.40 \pm 0.65$ vs $1.38 \pm 1.82 \mathrm{ng} / \mathrm{ml}: P<0.001)$ and pretreatment AMH level was a significant predictor of post-treatment amenorrhea $(P=0.001)$. No data are available on the differences between treatment arms (Leonard et al. 2012).

In the PROMISE-GIM6 phase III trial, 281 premenopausal breast cancer patients who were candidates for (neo)-adjuvant chemotherapy were randomly assigned to receive chemotherapy alone or combined with triptorelin for the prevention of chemotherapy-induced early menopause (Del Mastro et al. 2011). In a total of 26 patients, $\mathrm{AMH}, \mathrm{FSH}$, and $\mathrm{E}_{2}$ levels and menstrual activity were evaluated before chemotherapy, and every 3 months after chemotherapy (Giraudi et al. 2009). Levels of AMH were significantly lower $(1.26 \mathrm{ng} / \mathrm{ml})$ in women 40 years or older than in younger women $(2.97$ and $3.63 \mathrm{ng} / \mathrm{ml}$ in patients aged 25-36 and 37-40 years, respectively; $P=0.018$ ). After the administration of chemotherapy, the mean value of $\mathrm{AMH}$ significantly decreased from 2.04 to $0.59 \mathrm{ng} / \mathrm{ml}(P=0.0003)$. The mean decrease in AMH levels was not affected by the type of chemotherapy regimens $(P=0.97)$. Among ten patients with both early (0-5 months) and delayed (6-11 months) post-chemotherapy evaluations, no changes in AMH values were observed with longer follow-up: mean values were $1.49,0.35$, and $0.36 \mathrm{ng} / \mathrm{ml}$, at baseline, after 0-5 months, and after 6-11 months respectively. Menstrual activity resumption occurred in $48 \%$ of patients. In this preliminary analysis, baseline and post-chemotherapy values of AMH were not significantly associated with menstrual resumption (Giraudi et al. 2009).

\section{Discussion}

The studies conducted thus far are inconclusive regarding the role of AMH in patients treated for early breast cancer. Even if the function of this hormone as a marker of ovarian reserve seems to be well defined, the clinical impact for this group of patients is still unclear. Several questions remain in determining if we can consider $\mathrm{AMH}$ a useful clinical marker.

First of all, data regarding different regimens of chemotherapy are few, the number of patients involved in the studies is probably not adequate, and the trial designs are not comparable. For example, in Anderson's study, 42 patients received six different regimens of chemotherapy and eight different hormonal treatments (Anderson \& Cameron 2011). The chemotherapy containing cyclophosphamide and taxanes seemed to be more gonadotoxic, but because of the small number of participants, this cannot be regarded as conclusive (Anderson et al. 2011). It would be interesting to determine if all types of alkylating regimens decrease plasma levels of AMH in the same way and if the potential recovery can be influenced by the regimen received.

A major point to be clarified is the biological explanation of recovery of AMH post-chemotherapy. Post-chemotherapy increase in AMH levels is related to the renewal of pre-antral and small antral follicles pool, which are the main source of this hormone. Obviously, this recovery is observed only in patient with a partially reversible chemotherapy-induced ovarian damage. This recovery is probably influenced not only by the age of patients but also by other factors, such as the

Published by Bioscientifica Ltd. 
chemotherapy regimen used and other biological characteristics. Further studies are required in order to better clarify this topic and the specific toxicity of the different chemotherapy protocols.

AMH seems to be uninfluenced by the hormonal status of patients, but, the Partridge et al. (2010) and Anderson \& Cameron (2011) studies suggest a possible role of hormonal treatment in changing levels of $\mathrm{AMH}$ compared with baseline. Wider clinical records could confirm or refute these data.

An interesting perspective is the association between $\mathrm{AMH}$ and other markers of ovarian reserve $\left(\mathrm{FSH}, \mathrm{E}_{2}\right.$, and inhibin B). This association would be useful in determining why in patients in whom we detect premenopausal levels of FSH, AMH levels can differ from normal to undetectable. Is there a biological reason which we cannot explain? AMH could be useful only in the determination of ovarian reserve or could help the clinician to assess hormonal status post chemotherapy. Undetectable levels of AMH and elevated levels of FSH and LH can further confirm the menopausal status after chemotherapy.

As previously stated, determination of menopausal status in patients who have received chemotherapy is a pathophysiologic and clinical cornerstone especially important in choosing hormonal treatment, for example in switching from tamoxifene to an aromatase inhibitor (Guerrero et al. 2013).

Moreover, menopausal status cannot be defined in a considerable number of patients (Amir et al. 2009, 2010). One study suggests that AMH levels decrease to undetectable levels 5 years before the onset of the menopausal status (date of last menses), so undetectable plasma levels of AMH suggest a pending menopausal status (Sowers et al. 2008). However, longitudinal studies are required in order to establish if different or undetectable levels of $\mathrm{AMH}$ could predict timing of onset of postmenopausal status: this knowledge could be useful in the determination of menopausal status in chemotherapy-treated patients.

\section{Conclusion}

In the past few years, the issue of female fertility determination and preservation has assumed greater importance. $\mathrm{AMH}$ acts as an endocrine marker of follicle depletion, reflecting ovarian reserve and possibly the onset of the late stage of menopause transition. Nevertheless, the clinical role of AMH in patients with early breast cancer needs to be defined as well as its role in predicting treatment-induced infertility.
Further studies are awaited in order to define the regimen-specific action of chemotherapy on AMH levels, the percentage of post-treatment recovery of plasma levels of the hormone, and the relationship between menopausal status, infertility, and levels of AMH.

\section{Declaration of interest}

All authors take full responsibility for the content of the present publication; they confirm that the article reflect their viewpoint and medical experience. The content of the manuscript is not influenced by any pharma company. Authors did not receive any compensation for authoring the manuscript. No writing assistance was provided.

\section{Funding}

This work was partially supported by a Associazione Italiana per la Ricerca sul Cancro grant (IG 2013 N.14272).

\section{References}

Amir E, Seruga B, Freedman O \& Clemons M 2009 Amenorrhoea, menopause, and endocrine therapy for breast cancer. BMJ 3394261. (doi:10.1136/bmj.b4261)

Amir E, Freedman O, Allen L, Colgan T \& Clemons M 2010 Defining ovarian failure in amenorrheic young breast cancer patients. Breast 19 545-548. (doi:10.1016/j.breast.2010.06.003)

Anders C, Marcom PK, Peterson B, Gu L, Unruhe S, Welch R, Lyons P, Behera M, Copland S, Kimmick G et al. 2008 A pilot study of predictive markers of chemotherapy-related amenorrhea among premenopausal women with early stage breast cancer. Cancer Investigation 26 286-295. (doi:10.1080/07357900701829777)

Anderson R \& Cameron D 2011 Pretreatment serum anti-Müllerian hormone predicts long-term ovarian function and bone mass after chemotherapy for early breast cancer. Journal of Clinical Endocrinology and Metabolism 96 1336-1343. (doi:10.1210/jc.2010-2582)

Anderson RA, Themmen APN, Al-Qahtani A, Groome NP \& Cameron DA 2006 The effects of chemotherapy and long-term gonadotrophin suppression on the ovarian reserve in premenopausal women with breast cancer. Human Reproduction 21 2583-2592. (doi:10.1093/ humrep/del201)

Anderson RA, Nelson SM \& Wallace WH 2012 Measuring anti-Müllerian hormone for the assessment of ovarian reserve: when and for whom is it indicated? Maturitas 71 28-33. (doi:10.1016/j.maturitas.2011.11.008)

Anderson RA, Rosendahl M, Kelsey TW \& Cameron DA 2013 Pretreatment anti-Müllerian hormone predicts for loss of ovarian function after chemotherapy for early breast cancer. European Journal of Cancer 49 3404-3411. (doi:10.1016/j.ejca.2013.07.014)

Arbo E, Vetori DV, Jimenez MF, Freitas FM, Lemos N \& Cuhna-Filho JS 2007 Serum anti-Müllerian hormone levels and follicular cohort characteristics after pituitary suppression in the late luteal phase with oral contraceptive pills. Human Reproduction 22 3192-3196. (doi:10.1093/ humrep/dem258)

Bath LE, Wallace WHB, Shaw MP, Fitzpatrick C \& Anderson RA 2003 Depletion of ovarian reserve in young women after treatment for cancer in childhood: detection by anti-Müllerian hormone, inhibin B and ovarian ultrasound. Human Reproduction 18 2368-2374. (doi:10.1093/humrep/deg473)

van Beek RD, van den Heuvel-Eibrink MM, Laven JS, de Jong FH, Themmen AP, Hakvoort-Cammel FG, van den Bos C, van den Berg H, Pieters R \& de Muinck Keizer-Schrama SM 2007 AntiMüllerian hormone is a sensitive 
serum marker for gonadal function in women treated for Hodgkin's lymphoma during childhood. Journal of Clinical Endocrinology and Metabolism 92 3869-3874. (doi:10.1210/jc.2006-2374)

Behringer K, Mueller H, Goergen H, Thielen I, Eibl AD, Stumpf V, Wessels C, Wiehlputz M, Rosenbrock J, Halbsguth T et al. 2013 Gonadal function and fertility in survivors after Hodgkin lymphoma treatment within the German Hodgkin study group HD13 to HD15 trials. Journal of Clinical Oncology 31 231-239. (doi:10.1200/JCO.2012.44.3721)

Bentzen JG, Forman JL, Pinborg A, Lidegaard Ø, Larsen EC, Friis-Hansen L, Johannsen TH \& Nyboe Andersen A 2012 Ovarian reserve parameters: a comparison between users and non-users of hormonal contraception. Reproductive Biomedicine Online 25 612-619. (doi:10.1016/j.rbmo.2012. 09.001)

Brougham MFH, Crofton PM, Johnson EJ, Evans N, Anderson RA \& Wallace WH 2012 Anti-Müllerian hormone is a marker of gonadotoxicity in pre- and post-pubertal girls treated for cancer: a prospective study. Journal of Clinical Endocrinology and Metabolism 97 2059-2067. (doi:10.1210/jc.2011-3180)

Clemons M \& Simmons C 2007 Identifying menopause in breast cancer patients: considerations and implications. Breast Cancer Research and Treatment 104 115-120. (doi:10.1007/s10549-006-9401-y)

Cupisti S, Dittrich R, Mueller A, Strick R, Stiegler E, Binder H, Beckmann MW \& Strissel P 2007 Correlations between anti-Müllerian hormone, inhibin B, and activin A in follicular fluid in IVF/ICSI patients for assessing the maturation and developmental potential of oocytes. European Journal of Medical Research 12 604-608.

Deb S, Campbell BK, Pincott-Allen C, Clewes JS, Cumberpatch G \& Raine-Fenning NJ 2012 Quantifying effect of combined oral contraceptive pill on functional ovarian reserve as measured by serum anti-Müllerian hormone and small antral follicle count using three-dimensional ultrasound. Ultrasound in Obstetrics \& Gynecology 39 574-580. (doi:10.1002/uog.10114)

Decanter C, Morschhauser F, Pigny P, Lefebvre C, Gallo C \& Dewailly D 2010 Anti-Müllerian hormone follow-up in young women treated by chemotherapy for lymphoma: preliminary results. Reproductive Biomedicine Online 20 280-285. (doi:10.1016/j.rbmo.2009.11.010)

Del Mastro L, Boni L, Michelotti A, Gamucci T, Olmeo N, Gori S, Giordano M, Garrone O, Pronzato P, Bighin C et al. 2011 Effect of the gonadotropin-releasing hormone analogue triptorelin on the occurrence of chemotherapy-induced early menopause in premenopausal women with breast cancer. Journal of the American Medical Association 30 269-276. (doi:10.1001/jama.2011.991)

Dillon KE, Sammel MD, Prewitt M, Ginsberg JP, Walker D, Mersereau JE, Gosiengfiao Y \& Gracia CR 2013 Pretreatment antiMüllerian hormone levels determine rate of posttherapy ovarian reserve recovery: acute changes in ovarian reserve during and after chemotherapy. Fertility and Sterility 99 477-483. (doi:10.1016/j.fertnstert.2012.09.039)

Durlinger AL, Kramer P, Karels B, de Jong FH, Uilenbroek JT, Grootegoed JA \& Themmen AP 1999 Control of primordial follicle recruitment by anti-Müllerian hormone in the mouse ovary. Endocrinology 140 5789-5796. (doi:10.1210/en.140.12.5789)

Durlinger AL, Gruijters MJ, Kramer P, Karels B, Kumar TR, Matzuk MM, Rose UM, de Jong FH, Uilenbroek JT, Grootegoed JA et al. 2001 Anti-Müllerian hormone attenuates the effects of FSH on follicle development in the mouse ovary. Endocrinology 142 4891-4899. (doi:10.1210/en.142.11.4891)

Ebner T, Sommergruber M, Moser M, Shelb O, Schreier-Lechner E \& Tews G 2006 Basal level of anti-Müllerian hormone is associated with oocyte quality in stimulated cycles. Human Reproduction 21 2022-2026. (doi:10.1093/humrep/del127)

Elgindy EA, El-Haieg DO, Khorshid OM, Ismail EI, Abdelgawad M, Sallam HN \& Abou-Setta AM 2013 Gonadotrophin suppression to prevent chemotherapy-induced ovarian damage. Obstetrics and Gynecology 121 78-86. (doi:10.1097/AOG.0b013e31827374e2)

Fanchin R, Mendez Lozano DH, Frydman N, Gougeon A, di Clemente N, Frydman R \& Taieb J 2007 Anti-Müllerian hormone concentrations in the follicular fluid of the preovulatory follicle are predictive of the implantation potential of the ensuing embryo obtained by in vitro fertilization. Journal of Clinical Endocrinology and Metabolism 92 1796-1802. (doi:10.1210/jc.2006-1053)

Ganz P \& Hahn E 2008 Implementing a survivorship care plan for patients with breast cancer. Journal of Clinical Oncology 26 759-767. (doi:10.1200/JCO.2007.14.2851)

Garcia A, Grynnerup A \& Sorensen S 2012 The role of anti-Müllerian hormone in female fertility and infertility - an overview. Acta Obstetricia et Gynecologica Scandinavica 91 1252-1260. (doi:10.1111/ j.1600-0412.2012.01471.x)

Gerber B, von Minckwitz G, Stehle H, Reimer T, Felberbaum R, Maass N, Fischer D, Sommer HL, Conrad B, Ortmann O et al. 2011 Effect of luteinizing hormone-releasing hormone agonist on ovarian function after modern adjuvant breast cancer chemotherapy: the GBG 37 ZORO study. Journal of Clinical Oncology 29 2334-2341. (doi:10.1200/JCO. 2010.32.5704)

Giraudi S, Marroni P, Boni L, Bighin C, Levaggi A, Bini G, Taveggia P, Venturini M, Pronzato P \& Del Mastro L 2009 Anti-Müllerian hormone $(\mathrm{AMH})$ and ovarian function in young breast cancer $(\mathrm{BC})$ women receiving adjuvant chemotherapy (CT). Journal of Clinical Oncology 27 (Suppl) e11544.

Gougeon A, Ecochard R \& Thalabard JC 1994 Age-related changes of the population of human ovarian follicles: increase in the disappearance rate of non-growing and early-growing follicles in aging women. Biology of Reproduction 50 653-663. (doi:10.1095/biolreprod50.3.653)

Gracia C \& Jeruss JS 2013 Lives in the balance: women with cancer and the right to fertility care. Journal of Clinical Oncology 31 668-669. (doi:10.1200/JCO.2012.47.5798)

Gracia CR, Sammel MD, Freeman E, Prewitt M, Carlson C, Ray A, Vance A \& Ginsberg JP 2012 Impact of cancer therapies on ovarian reserve. Fertility and Sterility 97 134-140. (doi:10.1016/j.fertnstert.2011.10.040)

Guerrero A, Gavilà J, Folkerd E, Ortiz B, Martinez F, Garcia A, Climent MA, Guillem V \& Ruiz A 2013 Incidence and predictors of ovarian function recovery (OFR) in breast cancer (BC) patients with chemotherapyinduced amenorrhea (CIA) who switched from tamoxifen to exemestane. Annals of Oncology 24 674-679. (doi:10.1093/annonc/mds464)

Hadji P, Kauka A, Bauer T, Tams J, Hasenburg A \& Kieback DG 2012 Effects of exemestane and tamoxifen on hormone levels within the Tamoxifen Exemestane Adjuvant Multicentre (TEAM) trial: results of a German substudy. Climacteric 15 460-466. (doi:10.3109/13697137.2011. 647839)

Hazout A, Bouchard P, Seifer DB, Aussage P, Junca AM \& Cohen-Bacrie P 2004 Serum antiMüllerian hormone/Müllerian-inhibiting substance appears to be a more discriminatory marker of assisted reproductive technology outcome than follicle-stimulating hormone, inhibin B, or estradiol. Fertility and Sterility $914057-4063$.

Jemal A, Murray T, Samuels A, Ghafoor A, Ward E \& Thun MJ 2003 Cancer statistics, 2003. CA: A Cancer Journal for Clinicians 53 5-26. (doi:10.3322/canjclin.53.1.5)

Johnson JA, Tough S \& Society of Obstetricians and Gynaecologists of Canada 2012 Delayed child-bearing. Journal of Obstetrics and Gynaecology Canada 34 80-93.

Kallio S, Puurunen J, Ruokonen A, Vaskivuo T, Piltonen T \& Tapanainen JS 2013 AntiMüllerian hormone levels decrease in women using combined contraception independently of administration route. Fertility and Sterility 99 1305-1310. (doi:10.1016/j.fertnstert. 2012.11.034)

La Marca A, Stabile G, Artenisio AC \& Volpe A 2006 Serum anti-Müllerian hormone throughout the human menstrual cycle. Human Reproduction 21 3103-3107. (doi:10.1093/humrep/del291)

La Marca A, Sighinolfi G, Radi D, Argento C, Baraldi E, Artenisio AC, Stabile G \& Volpe A 2010 Anti-Müllerian hormone (AMH) as a predictive marker in assisted reproductive technology (ART). Human Reproduction Update 16 113-130. (doi:10.1093/humupd/dmp036) 
Lambertini M, Anserini P, Levaggi A, Poggio F \& Del Mastro L 2013 Fertility counseling of young breast cancer patients. Journal of Thoracic Disease 5 S68-S80. (doi:10.3978/j.issn.2072-1439.2013.05.22)

Larsen EC, Muller J, Rechnitzer C, Schmiegelow K \& Andersen AN 2003a Diminished ovarian reserve in female childhood cancer survivors with regular menstrual cycles and basal FSH $<10 \mathrm{IU} / 1$. Human Reproduction 18 417-422. (doi:10.1093/humrep/deg073)

Larsen EC, Muller J, Schmiegelow K, Rechnitzer C \& Andersen AN 2003b Reduced ovarian function in long-term survivors of radiation- and chemotherapy-treated childhood cancer. Journal of Clinical Endocrinology and Metabolism 88 5307-5314. (doi:10.1210/jc.2003-030352)

Lee SJ, Schover LR, Partridge AH, Patrizio P, Wallace WH, Hagerty K, Beck LN, Brennan LV \& Oktay K 2006 American Society of Clinical Oncology recommendations on fertility preservation in cancer patients. Journal of Clinical Oncology 24 2917-2931. (doi:10.1200/JCO.2006.06.5888)

Lee TH, Liu CH, Huang CC, Hsieh KC, Lin PM \& Lee MS 2009 Impact of female age and male infertility on ovarian reserve markers to predict outcome of assisted reproduction technology cycles. Reproductive Biology and Endocrinology 7 100. (doi:10.1186/1477-7827-7-100)

Lee S, Ozkavukcu N, Heytens E, Moy F, Alappat RM \& Oktay K 2011 Anti-Müllerian hormone and antral follicle count as predictors for embryo/oocyte cryopreservation cycle outcomes in breast cancer patients stimulated with letrozole and follicle stimulating hormone. Journal of Assisted Reproduction and Genetics 28 651-656. (doi:10.1007/ s10815-011-9567-z)

Lekamge DN, Barry M, Kolo M, Lane M, Gilchrist RB \& Tremellen KP 2007 Anti-Müllerian hormone as a predictor of IVF outcome. Reproductive Biomedicine Online 14 602-610. (doi:10.1016/S1472-6483(10)61053-X)

Leonard RC, Adamson D, Anderson R, Ballinger R, Bertelli G, Coleman RE, Fallowfield L, McLinden M, Mansi J \& Thomas G 2010 The OPTION trial of adjuvant ovarian protection by goserelin in adjuvant adjuvant chemotherapy for early breast cancer. Journal of Clinical Oncology 28590.

Leonard RC, Adamson D, Bertelli G, McLinden M, Haiying N, Dunlop J, Mansi J, Coleman RE, Thomas G \& Anderson R 2012 The relative value of anti-Müllerian hormone to predict premature menopause in patients receiving adjuvant chemotherapy for breast cancer: results from the OPTION trial. Journal of Clinical Oncology 301094.

Li HW, Wong CY, Yeung WS, Ho PC \& Ng EH 2011 Serum anti-Müllerian hormone level is not altered in women using hormonal contraceptives. Contraception 83 582-585. (doi:10.1016/j.contraception.2010.09.007)

Lie Fong S, Baart EB, Martini E, Schipper I, Visser JA, Themmen AP, de Jong FH, Fauser BJ \& Laven JS 2008a Anti-Müllerian hormone: a marker for oocyte quantity, oocyte quality and embryo quality? Reproductive Biomedicine Online 16 664-670. (doi:10.1016/S1472-6483(10)60480-4)

Lie Fong S, Lugtenburg PJ, Schipper I, Themmen AP, de Jong FH, Sonneveld P \& Laven JS 2008b Anti-Müllerian hormone as a marker of ovarian function in women after chemotherapy and radiotherapy for haematological malignancies. Human Reproduction 23 674-678. (doi:10.1093/ humrep/dem392)

Lie Fong S, Laven JS, Hakvoort-Cammel FG, Schipper I, Visser JA, Themmen AP, de Jong FH \& van den Heuvel-Eibrink MM 2009 Assessment of ovarian reserve in adult childhood cancer survivors using anti-Müllerian hormone. Human Reproduction 24 982-990. (doi:10.1093/humrep/den487)

Loren AW, Mangu PB, Beck LN, Brennan L, Magdalinski AJ, Partridge AH, Quinn G, Wallace WH \& Oktay K 2013 Fertility preservation for patients with cancer: American Society of Clinical Oncology clinical practice guideline update. Journal of Clinical Oncology 31 2500-2510. (doi:10.1200/JCO.2013.49.2678)

Lum SS, Woltering EA, Fletcher WS \& Pommier RF 1997 Changes in serum estrogen levels in women during tamoxifen therapy. American Journal of Surgery 173 399-402. (doi:10.1016/S0002-9610(97)00072-X)

Lutchman Singh K, Muttukrishna S, Stein RC, McGarrigle HH, Patel A, Parikh B, Groome NP, Davies MC \& Chatterjee R 2007 Predictors of ovarian reserve in young women with breast cancer. British Journal of Cancer 96 1808-1816. (doi:10.1038/sj.bjc.6603814)

Massagué J 1990 The transforming growth factor- $\beta$ family. Annual Review of Cell Biology 6 597-641. (doi:10.1146/annurev.cb.06.110190.003121)

Merlo DF, Ceppi M, Filiberti R, Bocchini V, Znaor A, Gamulin M, PrimicZakelj M, Bruzzi P, Bouchardy C \& Fucic A 2012 Breast cancer incidence trends in European women aged 20-39 years at diagnosis. Breast Cancer Research and Treatment 134 363-702. (doi:10.1007/s10549-012-2031-7)

Oktay K, Kim JY, Barad D \& Babayev SN 2010 Association of BRCA1 mutations with occult primary ovarian insufficiency: a possible explanation for the link between infertility and breast/ovarian cancer risks. Journal of Clinical Oncology 28 240-244. (doi:10.1200/JCO.2009. 24.2057)

Partridge A, Ruddy KJ, Gelber S, Schapira L, Abusief M, Meyer M \& Ginsburg E 2010 Ovarian reserve in women who remain premenopausal after chemotherapy for early stage breast cancer. Fertility and Sterility 94 638-644. (doi:10.1016/j.fertnstert.2009.03.045)

Rajpert-De Meyts E, Jørgensen N, Graem N, Müller J, Cate RL \& Skakkebaek NE 1999 Expression of anti-Müllerian hormone during normal and pathological gonadal development: association with differentiation of Sertoli and granulosa cells. Journal of Clinical Endocrinology and Metabolism 84 3836-3844. (doi:10.1210/jc.84.10.3836)

Randolph JF Jr, Crawford S, Dennerstein L, Cain K, Harlow SD, Little R, Mitchell ES, Nan B, Taffe J \& Yosef M 2006 The value of folliclestimulating hormone concentration and clinical findings as markers of the late menopausal transition. Journal of Clinical Endocrinology and Metabolism 91 3034-3040. (doi:10.1210/jc.2006-0243)

Rodriguez S, Campo-Engelstein L \& Emanuel L 2013 Fertile future? Potential social implications of oncofertility Journal of Clinical Oncology 31 665-667. (doi:10.1200/JCO.2012.44.0990)

Rosendahl M, Andersen CY, la Cour Freiesleben N, Juul A, Lossl K \& Andersen AN 2010 Dynamics and mechanisms of chemotherapyinduced ovarian follicular depletion in women of fertile age. Fertility and Sterility 94 156-166. (doi:10.1016/j.fertnstert.2009.02.043)

Ruddy KJ, Gelber S, Tamimi RM, Ginsburg ES, Schapira L, Come SE, Meyer ME, Winer E \& Partridge AH 2012 Biomarkers of amenorrhea and ovarian function in breast cancer survivors. Journal of Clinical Oncology 30 (Suppl) 9071.

Salama M, Winkler K, Murach KF, Seeber B, Ziehr SC \& Wildt L 2013 Female fertility loss and preservation: threats and opportunities. Annals of Oncology 24 598-608. (doi:10.1093/annonc/mds514)

Seifer DB, Mac Laughlin DT, Christian BP, Feng B \& Shelden RM 2002 Early follicular serum Müllerian-inhibiting substance levels are associated with ovarian response during assisted reproductive technology cycles. Fertility and Sterility 77 468-471. (doi:10.1016/S0015-0282(01)03201-0)

Shaw CM, Stanczyk FZ, Egleston BL, Kahle LL, Spittle CS, Godwin AK, Brinton LA \& Dorgan JF 2011 Serum antiMüllerian hormone in healthy premenopausal women. Fertility and Sterility 95 2718-2721. (doi:10.1016/j.fertnstert.2011.05.051)

Silberstein T, MacLaughlin DT, Shai I, Trimarchi JR, Lambert-Messerlian G, Seifer DB, Keefe DL \& Blazar AS 2006 Müllerian inhibiting substance levels at the time of HCG administration in IVF cycles predict both ovarian reserve and embryo morphology. Human Reproduction 21 159-163. (doi:10.1093/humrep/dei270)

Smeenk JM, Sweep FC, Zielhuis GA, Kremer JA, Thomas CM \& Braat DD 2007 AntiMüllerian hormone predicts ovarian responsiveness, but not embryo quality or pregnancy, after in vitro fertilization or intracyoplasmic sperm injection. Fertility and Sterility 87 223-226. (doi:10.1016/j.fertnstert.2006.06.019)

Smigal C, Jemal A, Ward E, Cokkinides V, Smith R, Howe HL \& Thun M 2006 Trends in breast cancer by race and ethnicity: update 2006. CA: A Cancer Journal for Clinicians 56 168-183. (doi:10.3322/canjclin. 56.3.168)

Smith IE, Dowsett M, Yap YS, Walsh G, Lonning PE, Santen RJ \& Hayes D 2006 Adjuvant aromatase inhibitors for early breast cancer after chemotherapy-induced amenorrhoea: caution and suggested 
guidelines. Journal of Clinical Oncology 24 2444-2447. (doi:10.1200/ JCO.2005.05.3694)

Sowers MR, Eyvazzadeh A, Mc Connell D, Yosef M, Jannausch ML, Zhang D, Harlow S \& Randolph JF Jr 2008 Anti-Müllerian hormone and inhibin B in the definition of ovarian aging and the menopause transition. Journal of Clinical Endocrinology and Metabolism 93 3478-3483. (doi:10.1210/jc.2008-0567)

Sowers M, McConnell D, Gast K, Zheng H, Nan B, McCarthy JD \& Randolph JF 2010 Anti-Müllerian hormone and inhibin B variability during normal menstrual cycles. Fertility and Sterility 94 1482-1486. (doi:10.1016/j. fertnstert.2009.07.1674)

Streuli I, Fraisse T, Pillet C, Ibecheole V, Bischof P \& de Ziegler D 2008 Serum antiMüllerian hormone levels remain stable throughout the menstrual cycle and after oral or vaginal administration of synthetic sex steroids. Fertility and Sterility 90 395-400. (doi:10.1016/j.fertnstert. 2007.06.023)

Su HI, Sammel MD, Green J, Velders L, Stankiewicz C, Matro J, Freeman EW, Gracia CR \& DeMichele A 2010 AntiMüllerian hormone and inhibin B are hormone measures of ovarian function in late reproductive-aged breast cancer survivors. Cancer 116 592-599. (doi:10.1002/cncr.24746)

Su HI, Flatt SW, Natarajan L, DeMichele A \& Steiner AZ 2013 Impact of breast cancer on anti-Müllerian hormone levels in young women. Breast Cancer Research and Treatment 137 571-577. (doi:10.1007/ s10549-012-2361-5)
Titus S, Li F, Stobezki R, Akula K, Unsal E, Jeong K, Dickler M, Robson M, Moy F, Goswami S et al. 2013 Impairment of BRCA1-related DNA double-strand break repair leads to ovarian aging in mice and humans. Science Translational Medicine 5 172ra21. (doi:10.1126/scitranslmed. 3004925)

Turner NH, Partridge A, Sanna G, Di Leo A \& Biganzoli L 2013 Utility of gonadotropin-releasing hormone agonists for fertility preservation in young breast cancer patients: the benefit remains uncertain. Annals of Oncology 24 2224-2235. (doi:10.1093/annonc/mdt196)

te Velde ER \& Pearson PL 2002 The variability of female reproductive ageing. Human Reproduction Update 8 141-154. (doi:10.1093/humupd/ 8.2.141)

Wallace WH, Anderson RA \& Irvine DS 2005 Fertility preservation for young patients with cancer: who is at risk and what can be offered? Lancet Oncology 6 209-218. (doi:10.1016/S1470-2045(05)70092-9)

Weenen C, Laven JS, Von Bergh AR, Cranfield M, Groome NP, Visser JA, Kramer P, Fauser BC \& Themmen AP 2004 Anti-Müllerian hormone expression pattern in the human ovary: potential implications for initial and cyclic follicle recruitment. Molecular Human Reproduction 10 77-83. (doi:10.1093/molehr/gah015)

Yu B, Douglas RA, Ferin DL, Nakhuda GS, Crew K, Lobo RA \& Hershman DL 2010 Changes in markers of ovarian reserve and endocrine function in young women with breast cancer undergoing adjuvant chemotherapy. Cancer 116 2099-2105. (doi:10.1002/cncr.25037)

Received in final form 17 October 2013

Accepted 28 November 2013

Made available online as an Accepted Preprint

29 November 2013
(C) 2014 Society for Endocrinology Printed in Great Britain
Published by Bioscientifica Ltd. 